\title{
Optimization of KY-crystallization process
}

\author{
Ie.V.Kryvonosov, L.A.Lytvynov \\ Institute for Single Crystals, STC "Institute for Single Crystals", \\ National Academy of Sciences of Ukraine, \\ 60 Nauky Ave., 61001 Kharkiv, Ukraine
}

Received October 16, 2016

The Kyropoulos method is an efficient means for growth of large high-quality single crystals. Technologists try to use the methods of numeral simulation for analytical calculation of thermodynamic conditions of crystallization and the choice of optimal technological regimes. However, these methods do not permit to effectively use the calculation results for prediction of the crystal growth dynamics and correction of the crystallization regime. In the present work it is described a method for optimization of sapphire crystallization process, based on the analysis of dynamic characteristics of the virtual image of the real technological process.

Keywords: Kyropoulos method, high-quality single crystals, sapphire crystal.

\begin{abstract}
Метод Киропулоса - перспективный метод для выращивания крупных монокристаллов высокого качества. Технологи пытаются оптимизировать технологический процесс, используя методы аналитического расчёта теплофизических условий кристаллизации и әкспериментальный подбор оптимальных режимов роста. Однако, эти методы не позволяют әффективно использовать результаты расчета для прогнозирования динамики роста кристалла и коррекции режима кристаллизации. В работе описан метод оптимизации процесса кристаллизации сапфира, основанный на анализе динамических характеристик виртуального образа реального технологического процесса.
\end{abstract}

Оптимізація КУ-процесу кристалізації. Є.В.Кривоносов, Л.А.Литвинов.

Метод Кіропулоса - перспективний метод для вирощування крупних монокристалів високої якості. Технологи намагаються оптимізувати технологічний процес, використовуючи методи аналітичного розрахунку теплофізичних умов кристалізації та експериментальний підбір оптимальних режимів зростання. Проте, ці методи не дозволяють ефективно використовувати результати розрахунку для прогнозування динаміки вирощування кристала і корекції режиму кристалізації. У роботі описано метод оптимізації процесу кристалізації сапфіра, заснований на аналізі динамічних характеристик віртуального образу реального технологічного процесу.

\section{Introduction}

The Kyropoulos (KY) method is an efficient means for growth of large high-quality sapphire. The main drawback of this method is an absence of information about dynamic parameters of the growth process. Technologists try to overcome this drawback by using the methods of analytical calculations of the thermal conditions of crystallization and experimental choice of the optimum growth conditions.
There have been developed computer programs for calculation and numerical simulation of temperature fields in the growth zone formed by different systems of reflecting and heat-insulating shields [1-6]. However, these programs do not consider the dynamics of the change in parameters of the real crystallization process. Only after solving this problem, the process of crystal growth will be controlled and optimized. In the present work, which is development of 
the studies reported in [7-9], the method of optimization of the crystallization technological conditions is proposed, which allows to control the crystallization rate and the shape of the growing crystal.

\section{Preconditions for optimization of crystallization process}

During the sapphire growth by the KYmethod, the shape of the crystallization front constantly changes, that substantially influences the shape of the growing crystal and the crystallization rate. Therefore, control of the crystallization front shape is one of the basic conditions for optimization of the crystallization process.

On the basis of computer simulation of virtual technological process, there was proposed the method of analytical analysis of the basic dynamic parameters for every particular process of the KY-method crystallization [7-9]. The virtual image is simulated on the assumption that the crystallization front is shaped as cone with a varying angle $(\alpha)$ at the vertex. The angle $\alpha$ is used in the capacity of the value of the parameter of the crystallization front shape (CFS-parameter) for mathematical description of the dynamics of changes in the crystallization front shape. The effectiveness of this approach has been confirmed when growing sapphire crystals weighing $85 \mathrm{~kg}$ by our method on industrial scale by "LG Siltron Inc." (Korea) [10]. The simulation results are presented in graphical and numerical form, that allows to analyze the functional connection between the dynamic parameters of the crystallization process and the qualitative characteristics of the growing crystal.

The crystallization process consists of three characteristic stages. There are: 1) crystal seeding and shouldering (the initial stage); 2) crystal growth till the moment when the vertex of the crystallization front cone touches the bottom of the crucible (the linear stage); 3) crystal growth accompanied with the change of the crystallization front shape till full completion of the process (the final stage).

The crystal quality is mainly defined by the dynamic characteristics of Stage 1 and partially by those of Stage 2. By the beginning of Stage 3 the vertex of the crystallization front reaches the crucible bottom and the crystal structure quality is already formed, thereat the crystallization conditions remain practically unchanged. Therefore, to optimize the whole crystallization process the analysis of the first two stages is needed.

Optimization of the growth process implies establishment of the technological conditions which provide the obtaining of crystals of regular shape without inclusions of other phases and structural macroscopic defects in the crystal bulk. The crystallization rate is the main factor affecting the structural quality of the crystals. It essentially depends on the dynamics of changes in the shape of the crystallization front during the process. At the stage of shouldering the crystallization front has most unstable shape, that causes abrupt changes of the crystallization rate and, as a result, capture of inclusions of other phases, formation of blocks and distortion of the growing crystal profile.

The crystallization front shape is defined by the configuration of the thermal field of the used growth setup. Due to degradation of the construction elements of the thermal unit in the process of exploitation, the thermal characteristics of the crystallizer constantly vary during each growth process, and such variations accumulate. Therefore, after 5 or 6 successive crystallization cycles the technological conditions must be corrected.

\section{Methods for optimization of technological processes}

Sapphire crystal with weight of $70 \mathrm{~kg}$ was grown using the setup "Omega-300KS". Correction of crystallization conditions for the given growth equipment was based on analysis of the dynamic parameters of the technological process for this setup. By means of the computer program of dynamic calculator "SK Forecast" there was created the virtual image of this technological process [9]. For this purpose we took into account the information on shape of the growing crystal, the dynamics of changes in its weight and the rate of pulling the crystal from the melt during the crystallization process (Fig. 1).

The virtual image allowed to reveal those situations in the technological process, when the crystal profile was distorted, or the crystallization rate exceeded the critical one. In particular, due to non-monotonic change of the value of CFS-parameter, the axial crystallization rate was found to change within wide limits. Thereat, the said rate had the maximum value $\left(v_{c r}>\right.$ $5.5 \mathrm{~mm} / \mathrm{h}$ ) when the length of the growing crystal above the melt was $20 \mathrm{~mm}$ and $75 \mathrm{~mm}$, the minimum value $\left(\mathrm{v}_{c r} \approx-\right.$ 

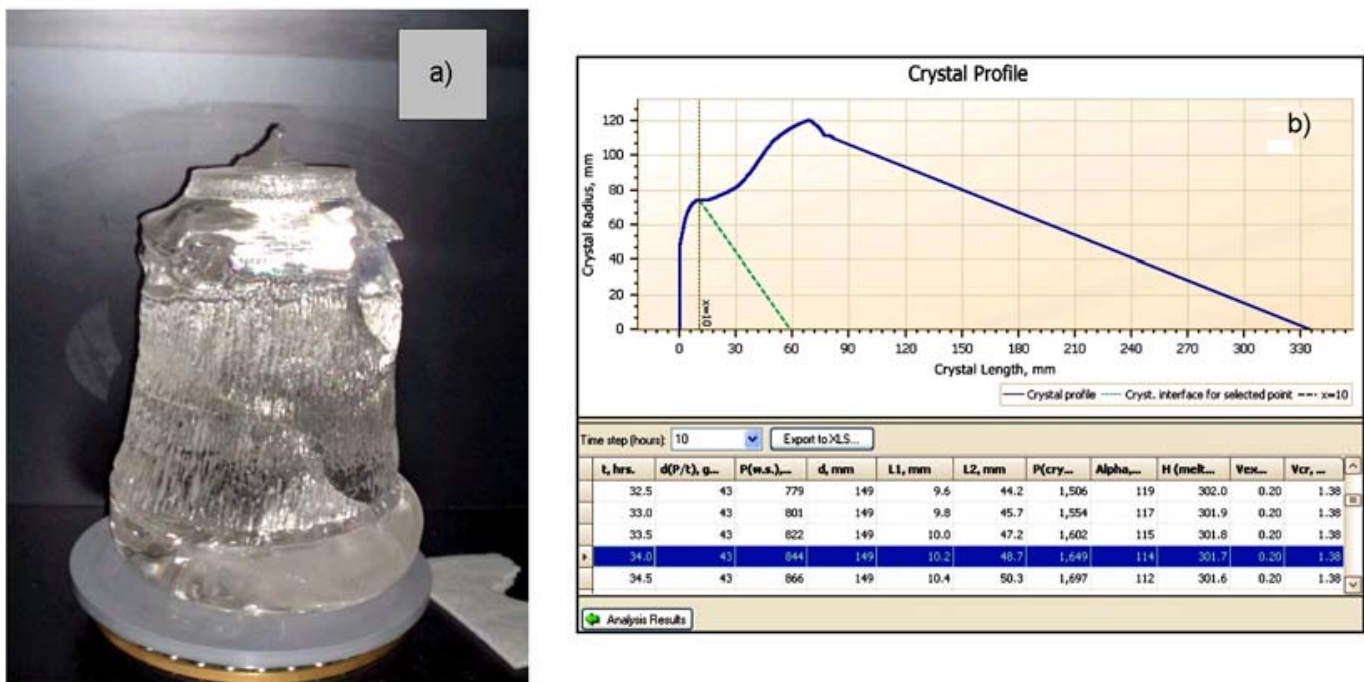

Fig. 1. Virtual image of process of sapphire crystallization $(70 \mathrm{~kg})$ : a - view of grown crystal; b - simulation results for 1st and 2nd stages of the crystallization process.

$2.0 \mathrm{~mm} / \mathrm{h}$ ) corresponded to length of $45 \mathrm{~mm}$ (Fig. 2).

At the crystallization process the profile of the growing crystal is influenced by the dynamics of changes in the current intensity on the heater, the rate of crystal pulling from the melt and changes in the crystallization front shape. The current on the heater and the rate of crystal pulling are controlled parameters. The crystallization front shape is defined by configuration of thermal field in the crystallization zone and heat removal through the crystal from the crystallization front. The latter factor depends on the shape of the growing crystal over the melt, which affects the CFS-parameter. As the crystal diameter $(d)$ on the surface of melt increases, the value of CFSparameter ( $\alpha$ angle) rises, but it decreases at the increase of the crystal length $(L)$ over the melt. Parametric analysis of the virtual image of the performed crystallization makes it possible to establish the functional dependence $\alpha_{i}=f\left(d_{i} / L_{i}\right)$, where $d / L$ is the parameter of the growing crystal shape. The obtained relation permits to determine the CFS parameter values for the desired profile of the future crystal. We simulated the new technological process of the crystal growth taking into account limitations of the crystallization rate in the range of $2.5 \ldots 3 \mathrm{~mm} / \mathrm{h}$ (Fig. 3) by means of program "SK Forecast". This program calculates the dynamics of changes in the rate of crystal pulling from the melt and changes in the readings of the sensor of the growing crystal weight.

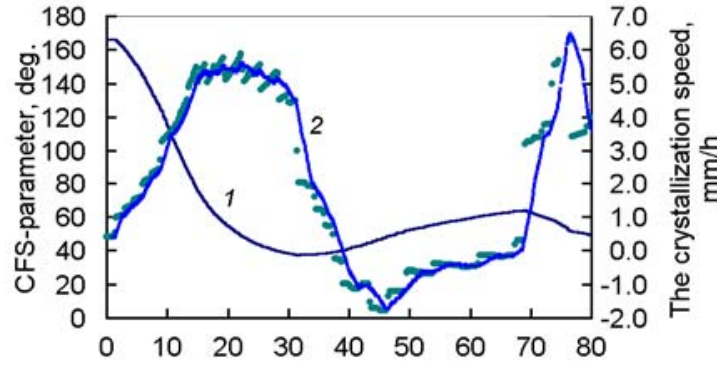

Fig. 2. Dynamic characteristics of crystallization front of sapphire (weighing $70 \mathrm{~kg}$ ): 1 - CFS-parameter (the angle $\alpha$ ); 2 - rate of motion of crystallization front vertex.

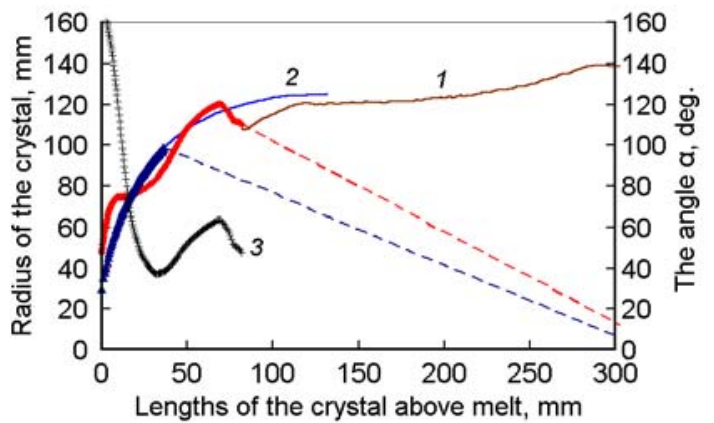

Fig. 3. Correction of crystal profile for initial stage of crystallization taking into account CFS-parameter: 1 - crystal profile of previous real process; 2 - crystal profile of optimized process; 3 - CFS-parameter (the angle $\alpha$ ) of the real process.

To calculate the dynamics of changes in intensity of current on the heater, there was used the functional dependence $\left(P_{c r}\right)_{i}=$ $f\left(W_{i}\right)$ between the total weight of the grow- 


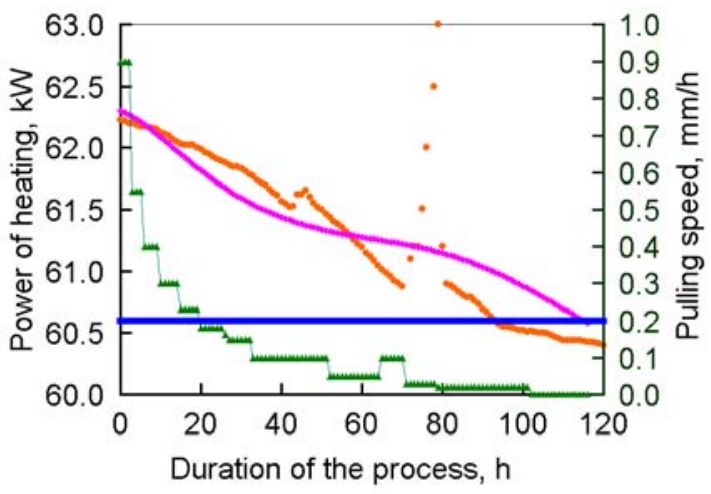

Fig. 4. Technological parameters of the stage of sapphire shouldering before and after corrections of dynamic characteristics of crystallization process: 1 - power of heating (previous real process); 2 - power of heating (optimized process); 3 pulling rate (previous real process); 4 - pulling rate (optimized process).

ing crystal $\left(P_{c r}\right)$ and consumed power $(W)$ of the heater while growing the real crystal. This relationship established in Microsoft Excel format from the digital data of simulation of the virtual image of the growing crystal was used to calculate the dynamics of changes in the consumed power of the heater to optimize the next process.

The crystallization process realized in accordance with the calculated dynamics of the CFS parameter, changes of the consumed power of the heater and the rate of crystal pulling from the melt provides the formation of crystal boules of a desired shape (Fig. 4).

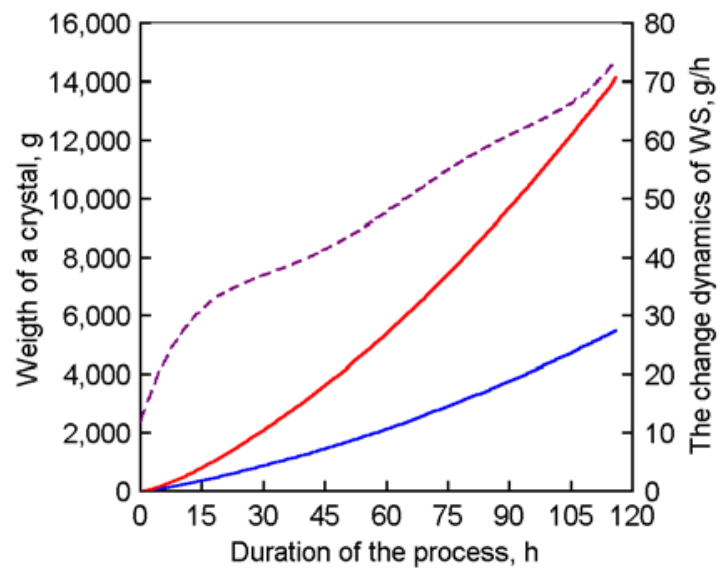

Fig. 5. Controlled technological parameters at the initial stage of crystallization process: 1 weight sensor reading (WS); 2 - total crystal weight; 3 - dynamics of WS change.

In the crystallization process the crystal weight sensor controls the resultant action of the growing crystal weight and the buoyancy force of the melt which undergoes the crystal, on the crystal holder. The computer program "SK Forecast" calculates the basic technological parameters of the crystallization process to be implemented and controlled (Fig. 5).

The total cycle of the optimization process implies successive analysis of the dynamic characteristics of the fulfilled crystallization, correction of the technological conditions for realization of subsequent crystallization processes, calculation and prediction of the growth regimes corresponding to the new technological condi-

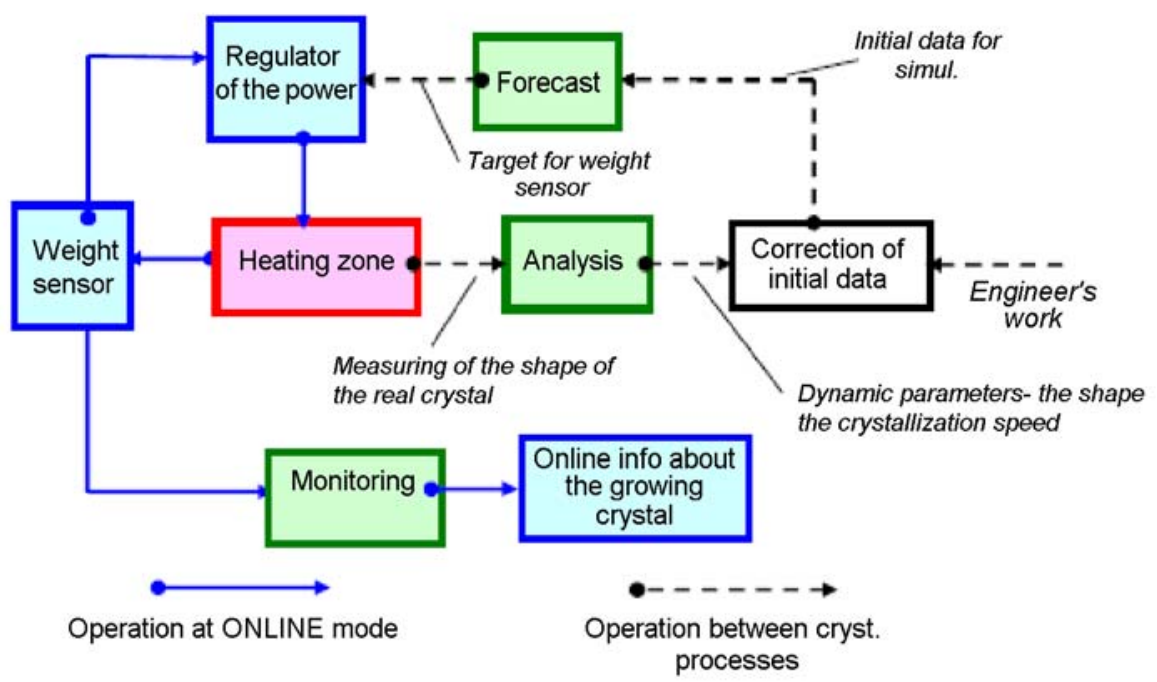

Fig. 6. Scheme of optimization cycle of sapphire crystallization by KY-method. 
tions of crystal growth. The program "SK Forecast" makes it possible to visualize the crystallization situation inside the crucible on a computer monitor in the crystallization process. This is provided by dynamic analysis of the technological regimes and control of the current values of the crystal pulling rate and the weight sensor readings during crystallization (Fig. 6). Such an optimization cycle is individual for each crystal growth setup and it is to be carried out after each 5 or 6 crystallization processes.

\section{Conclusions}

Dynamic analysis of the grown crystal makes it possible to realize correction and optimization of technological conditions for subsequent crystallization processes. Thereat, the said correction concerns the crystallization rate, the rate of crystal pulling from the melt, the dynamics of changes in the consumption power of heater and the weight sensor readings. These characteristics are entered into technological computer of the growth equipment and used for controlling each crystallization process. The heating power regulator provides preset crystallization rate and dynamics of changes in the growing crystal weight which is con- trolled by the weight sensor. The crystal profile formed by changing the rate of crystal pulling from the melt. The controlled limitations minimize the possibility of formation of blocks and inclusions of another phase in the bulk of the growing crystal.

\section{References}

1. S.E.Demina, E.N.Bystrova, M.A.Lukanina et al., J.Opt. Mater., 30, 62 (2007).

2. S.E.Demina, V.V.Kalaev, J. Cryst. Growth, 320, 23 (2011).

3. V.M.Mamedov, S.A.Rukolaine, Math.Model., 16, 15 (2004).

4. W.J.Lee, Y.C.Lee, H.H.Jo, Y.H.Park, J. Cryst. Growth, 332, 120 (2011).

5. Zhang Lunyong, Zuo Hongbo, Sun Jianfei et al., Cryst. Res. Technol., 46, 1019 (2011).

6. Zhang Lunyong, Zuo Hongbo, Cao Fuyang et al., Cryst. Res. Technol., 47, 175 (2012).

7. Ie.V.Kryvonosov, D.I.Kryvonosov, P.V.Konevskyi, L.A.Lytvynov, Proc. 17th Intern. Conf. on Crystal Growth and Epitaxy, University of Warsaw, Poland (2013), p.97.

8. Patent UA 103465 U (2015).

9. Ie.V.Kryvonosov, L.A.Lytvynov, Functional Materials, 23, 300 (2016).

10. Do Won Song, Kwang Seok Kim, Hyo Kim, Korean J.Chem.Eng., 32, 486 (2015). 